\title{
Sacrifice and Service, Protectors and Teachers: The Role of Military and Veteran Patients in Training Early-Career Psychiatrists
}

\author{
Laura Weiss Roberts ${ }^{1}$
}

Received: 27 April 2015 / Accepted: 29 April 2015 / Published online: 16 June 2015

(C) Academic Psychiatry 2015

The USA is home to more than 2 million active military members and reservists and 21 million veterans $[1,2]$. Beyond their immense service in protecting this country, active military members and veterans are our great partners in academic medicine. It is estimated that two thirds of US physicians and half of US psychologists in practice received some portion of their clinical education at Veterans Administration (VA) hospitals [3]. In 2013, the VA had 118,799 clinical trainees [3]. The VA has created and sustained our nation's largest integrated health care system, which is organized into 23 regional networks [4]. Most VA medical centers (124 of 152) are affiliated with allopathic and osteopathic medical schools, including military medical training facilities [3]. Further, the VA's medical centers and independent clinics are also affiliated with more than 1800 unique colleges and universities [3]. Veterans and members of the active military and reserves are not only our country's defenders - they are the teachers of our country's health professionals.

The mental health concerns of veterans, members of the active military, and reservists are immense, and this fact makes the partnership between academic medicine and the VA and military medical system particularly salient for academic psychiatry. A veteran commits suicide nearly every hour (21-22/day), a rate that is double that of the general population and that has been escalating more rapidly than the general population [5,6]. Mental disorders are the leading cause of hospitalization of members of the armed forces [6]. Approximately one-half million veterans are "service connected" for a significant mental illness, and veterans with

Laura Weiss Roberts

acadpsych@gmail.com

1 Stanford University School of Medicine, Stanford, CA, USA direct combat experience are especially burdened with posttraumatic stress disorder, depression, anxiety, and substancerelated conditions [7]. For these reasons, the VA has defined priorities related to recovery, coordinated and holistic care, mental health-primary care integration, around-the-clock service, gender- and culture-sensitive care, evidence-based treatments, community-based care, and care that engages families [8]. These initiatives represent key opportunities for clinical education, providing innovative, forward-looking, and outcomes-oriented training experiences.

In this issue of Academic Psychiatry, Lieutenant Colonel Christopher Warner has assembled an outstanding collection of peer-reviewed papers focusing on the role of the military and veterans in academic psychiatry. I met Lt Colonel Warner not too many years ago through one of these partnerships when he was a Ginsburg Fellow for the American Association of Directors of Psychiatric Residency Training. Shortly thereafter, he completed his training and was serving as a Division Psychiatrist where he carried tremendous responsibility for the mental health of his military colleagues in Iraq. Now Warner serves as the Consultant to the US Army Surgeon General for Psychiatry, a senior military mental health advisor in the US Army. He graduated from the US Military Academy at West Point and received his medical degree from the Uniformed Services University of Health Sciences. Warner is dually trained in family medicine and psychiatry, and he currently serves as one of the two US delegates to the North Atlantic Treaty Organization Research and Policy Group on Mental Health and Moral Dilemmas. Warner has served in many leadership roles in the US military, including as the Division Surgeon for the 101st Airborne Division and an integral member of the medical planning team for Operation United Assistance in Liberia. His operational deployments also include two rotations to Iraq in support of Operation Iraqi Freedom. Warner's awards, decorations, and honors are numerous and 
include twice receiving the Bronze Star, the Expert Field Medical Badge, and the Combat Action Badge. Warner has served as an author and reviewer for our journal, Academic Psychiatry, for more than 10 years, and we are honored that he put this special collection together for our readership.

The editors wish to offer our thanks to Dr. Warner and to the authors who contributed to this special collection, which is unique in the medical and educational literature. In his guest editorial, Lt Colonel Warner has provided an overview of the papers [9]. I wish to highlight the thoughtfulness and logic of the collection, which, first, provides information on military medical training and culture; second, illustrates the perspectives and experiences of residents, clinical supervisors and teachers, and administrative leaders in the context of military psychiatry; third, offers descriptions of novel and interesting curricula and evaluative efforts; fourth, gives information about subspecialty training in military psychiatry; and, finally, gives focus to sustained academic career development among military psychiatrists. Through this unique collection, we have the opportunity to "peak behind the curtain," learning more about the military, about training in military medicine, and about the relationship of military medicine to academic psychiatry.

This collection has special meaning for me. My formation as a physician was very much influenced by the active military and veteran patients I cared for during my psychiatry residency training. I remember well the Vietnam War combat survivors who viewed me as impossibly young and naïve and yet, in time, allowed me to learn about the defining, unimaginable experiences of their lives. I remember well how veterans on every inpatient ward naturally formed "units," with the stronger and more able gathering up - with respect and equalitythe weaker and more disabled in order to face, together as brothers, the challenges of the day. I remember well the soldiers on active duty who would say little, courageously attempting to handle their hardest moments alone and desperately managing the shame and stigma that they felt. I remember the soldier who was embarrassed by his depression, feeling that he did not deserve to be ill or to receive help because, unlike his peers, he was not in harm's way. I will never forget the women soldiers who felt completely alone and how their wellbeing returned with the acceptance and support of their fellow warriors. I will never forget the homeless veterans who had long-accepted the injustice of their lives. Most of all, I will never forget the one Native American warrior, easily twice my size, who had volunteered for three tours of duty and had experienced far more of life's sorrows than its joys. These patients taught me about the universality of heroism and of suffering. These members of the military and veterans helped me understand how courage and vulnerability coexist, how listening without judgment can help someone bear their burdens, and how astute clinical care can turn things for the better-including for those great men and women whose service has allowed our lives to be better.

Disclosure The author states that there is no conflict of interest.

\section{References}

1. National Center for Veterans Analysis and Statistics. Veteran Population. Available at http://www.va.gov/vetdata/Veteran Population.asp. Accessed April 22, 2015.

2. Global Firepower. United States Military Strength. Available at http://www.globalfirepower.com/country-military-strength-detail. asp?country_id=united-states-of-america. Accessed April 22, 2015.

3. US Department of Veterans Affairs, Office of Academic Affiliations. Mission of the Office of Academic Affiliations. Available at http:// www.va.gov/oaa/oaa mission.asp. Accessed April 22, 2015.

4. US Department of Veterans Affairs. Locations: Veterans Health Administration. Available at http://www.va.gov/directory/guide/ division.asp?dnum=1. Accessed April 22, 2015.

5. Kemp J, Bossarte R. Suicide Data Report, 2012. Department of Veterans Affairs Mental Health Services Suicide Prevention Program. Available at http://www.va.gov/opa/docs/Suicide-DataReport-2012-final.pdf. Accessed April 22, 2015.

6. American Psychiatric Association. Military. Available at http://www. psychiatry.org/military. Accessed April 22, 2015.

7. National Alliance on Mental Illness. Policy topics: veterans living with severe mental illness. Available at http://www2.nami.org/ Template.cfm?Section=Issue_Spotlights\&template $=/$ ContentManagement/ContentDisplay.cfm\&ContentID=23044. Accessed April 22, 2015.

8. South Central Veterans Integrated Service Network (VISN) 16 Mental Illness Research, Education, and Clinical Center (MIRECC) Consumer Guide Workgroup, Sullivan G, Arlinghaus K, Edlund C, Kauth M, Kemp J, Kelly K. Guide to VA mental health services for veterans \& families. Washington DC, US Department of Veterans Affairs, July 2012. Available at http://www.mentalhealth. va.gov/docs/MHG_English.pdf.

9. Warner $\mathrm{CH}$. A decade of war: adapting to meet the mental health training demands. Acad Psychiatry. 2015. doi:10.1007/s40596-0150365-2. 